human prions by hydrogen peroxide gas plasma sterilization. Infect Control Hosp Epidemiol 2009;30:769-777.

17. Jackson GS, McKintosh E, Flechsig E, et al. An enzyme-detergent method for effective prion decontamination of surgical steel. J Gen Virol 2005;86: 869-878.

18. Taguchi F, Tamai Y, Uchida A, et al. Proposal for a procedure for complete inactivation of the Creutzfeldt-Jakob disease agent. Arch Virol 1991;119: 297-301.

19. Fichet G, Comoy C, Duval C, et al. Novel methods for disinfection of prion-contaminated medical devices. Lancet 2004;364:521-526.

20. Fichet G, Comoy E, Dehen C, et al. Investigations of a prion infectivity assay to evaluate methods of decontamination. $J$ Microbiol Methods 2007;70:511-518.

21. Peretz D, Supattapone S, Giles K, et al. Inactivation of prions by acidic sodium dodecyl sulfate. $J$ Virol 2006;80:322-331.

22. Taylor DM, Fraser H, McConnell I, et al. Decontamination studies with the agents of bovine spongiform encephalopathy and scrapie. Arch Virol 1994;139:313-326.

23. Vadrot C, Darbord J-C. Quantitative evaluation of prion inactivation comparing steam sterilization and chemical sterilants: proposed method for test standardization. J Hosp Infect 2006;64:143-148.

24. Taylor DM, McConnell I. Autoclaving does not decontaminate formolfixed scrapie tissues. Lancet 1988;1(8600):1463-1464.

25. Taylor DM. Inactivation of prions by physical and chemical means. $J$ Hosp Infect 1999;43 (suppl):S69-S76.

26. Brown P, Gibbs CJ, Rodgers-Johnson P, et al. Human spongiform encephalopathy: the National Institutes of Health series of 300 cases of experimentally transmitted disease. Ann Neurol 1994;35:513-529.

27. Rutala WA, Weber DJ. Creutzfeldt-Jakob disease: recommendations for disinfection and sterilization. Clin Infect Dis 2001;32:1348-1356.

28. Association for peri-Operative Registered Nurses. Recommended practices for cleaning and care of surgical instruments and powered equipment. In: Association for peri-Operative Registered Nurses, ed. Perioperative Standards and Recommended Practices. Denver: Association for peri-Operative Registered Nurses; 2009:629.

29. Rutala WA; 1994, 1995, and 1996 APIC Guidelines Committee. APIC guideline for selection and use of disinfectants. Association for Professionals in Infection Control and Epidemiology. Am J Infect Control 1996;24:313-342.

30. Rutala WA, Weber DJ. Cleaning, disinfection and sterilization. In: Carrico $\mathrm{R}$, ed. APIC Text of Infection Control and Epidemiology. Washington, DC: Association for Professionals in Infection Control and Epidemiology; 2009.

31. Association for the Advancement of Medical Instrumentation (AAMI). Comprehensive guide to steam sterilization and sterility assurance in health care facilities. National Standards Institute/AAMI ST79. 2006.

32. Kohn WG, Collins AS, Cleveland JL, et al; Centers for Disease Control and Prevention. Guidelines for infection control in dental healthcare settings-2003. MMWR Recomm Rep 2003;52(RR-17):1-61.

\section{The Rationale of Guidelines for Infection Control in Dentistry: Precautionary Principle or Acceptable Risk?}

To the Editor-Infection control in dentistry is aimed at reducing the occupational risk of infections among dental healthcare personnel and the risk of healthcare-associated infections among patients. ${ }^{1}$ The level of risk and the appro- priateness of infection control measures are assessed and modeled according to the available scientific evidence. Unfortunately, such evidence is frequently incomplete, ${ }^{2}$ thus leaving room for the application of the precautionary principle, which states that when an activity presents an uncertain potential for substantial harm to human health, precautionary measures should be taken even if there is no scientific evidence that such measures are needed or effective. The precautionary principle is extensively acknowledged and frequently applied in public health. For example, precautionary principle-based measures have been applied worldwide to control pandemic H1N1 influenza A, although they have recently been declared unjustified and expensive by the Council of Europe. ${ }^{3}$

Some precautionary principle-based preventive measures for infection control in dentistry are directed at activities that pose a negligible risk of infection, resulting in unnecessary costs and, occasionally, detrimental effects. The following examples illustrate this point.

1. Although dental therapy with use of handpieces may produce a retraction of oral fluids from patients to dental unit waterlines, scientific evidence suggests that contamination of dental unit waterlines is not implicated in the transmission of bloodborne pathogens. ${ }^{4}$ Nevertheless, most guidelines include measures to prevent such risk.

2. Although invasive dental therapy is a source of transient bacteremia, the risk of bacterial endocarditis is limited to immunocompromised patients and those with artificial heart valves. ${ }^{5}$ Nevertheless, most guidelines recommend that patients use a mouthwash before dental therapy to decrease the risk of bacterial endocarditis.

3. According to the Centers for Disease Control and Prevention (CDC), semicritical instruments, such as dental mirrors and probes, which touch mucous membranes, have a low risk of transmission of bloodborne pathogens and must be sterilized with heat after use. ${ }^{1}$ However, maintaining the sterility of processed items after sterilization is a different matter, because there is no scientific evidence that contamination of semicritical instruments by environmental microorganisms increases the risk of infection. Nevertheless, most guidelines recommend maintaining the sterility of processed semicritical instruments after sterilization.

4. Opportunistic pathogens, such as Legionella pneumophila and Pseudomonas aeruginosa, may colonize dental unit waterlines. However, the risk of infection among dental patients and healthcare personnel exposed to water contaminated by these microorganisms is minimal, because the bacterial load produced during therapy and their spread in the environment is low. ${ }^{6}$ Nevertheless, most guidelines recommend disinfection of dental unit waterlines, ${ }^{7}$ thus posing a risk of toxic effects.

The effectiveness of guidelines in decreasing the risk of infection in dentistry is not debatable, as demonstrated by 
the declined incidence of bloodborne and airborne infections in dentistry after the extensive dissemination of the guidelines developed by the CDC. ${ }^{8}$ However, some measures based on the precautionary principle have failed in their goal of preventing the transmission of pathogens. For example, it has been shown that the dental healthcare personnel involved in the only case of hepatitis B virus transmission from patient to patient ever documented in the history of dentistry followed the standard procedures to prevent the transmission of bloodborne pathogens. ${ }^{9}$ In addition, although the majority of cases of $\mathrm{H} 1 \mathrm{~N} 1$ influenza A virus transmission occurred in the workplace, household, and school and there was only 1 suspected case of nosocomial transmission from healthcare staff to patient in high-income countries-not related to dental healthcare ${ }^{10}$-measures to prevent such transmission in dentistry have been developed and disseminated. These examples suggest that guidelines based on the precautionary principle may occasionally be ineffective in decreasing the risk of infection, either because the risk is overestimated or because the routes of transmission are unknown.

As members of a working group charged by the Italian Ministry of Health, we developed the Italian guidelines for infection control in dentistry. ${ }^{11}$ The underlying principle of these guidelines was that infection control procedures cannot seek to eradicate infection transmission but can realistically seek to reduce the excess risk of infection to an acceptable level. The term acceptable risk, which evolved from the realization that absolute safety is generally an unachievable goal, describes the likelihood of an event whose probability of occurrence is small. Indeed, if recommendations to decrease the incidence of healthcare-associated infection are based on risk ${ }^{2}$ (see also the recommendations on patient safety released in 2009 by the Council of Europe) ${ }^{12}$ it is not clear why guidelines for infection control in dentistry must be based on contamination or the precautionary principle. According to the guidelines released by the European Commission in 2000 regarding the correct application of the precautionary principle, measures based on it must be periodically reviewed, and if there is new scientific evidence regarding effectiveness and consequences, such measures must be revised accordingly. ${ }^{13}$ Instead, updates of infection control guidelines in dentistry generally produce new measures in addition to the previous measures, thus obtaining an endless series of automatic procedures and processes. This could make dental healthcare personnel less aware of which dental procedures yield the highest risk of transmission of bloodborne pathogens on the basis of the scientific evidence-that is, carelessly handling sharp instruments, which increases the risk of percutaneous injuries. ${ }^{8,14}$ Paradoxically, percutaneous injuries are not preceded by contamination. Therefore, to prevent the risk of inattention on the part of dental healthcare personnel, it would be advisable to grade the recommendations developed by the guidelines according to the scientific evidence of the levels of risk of infection and of effectiveness of preventive measures.

\section{ACKNOWLEDGMENTS}

Potential conflicts of interest. All authors report no conflicts of interest relevant to this article.

\section{Stefano Petti, DMD; Antonella Polimeni, MD}

From the Department of Public Health and Infectious Diseases (S.P.) and the Department of Dental and Maxillofacial Sciences (A.P.), Sapienza University, Rome, Italy.

Address reprint requests to Stefano Petti, DMD, Department of Public Health and Infectious Diseases, Sanarelli Hygiene Building, Sapienza University, Piazzale Aldo Moro 5, 00185 Rome, Italy (stefano.petti@uniromal.it). Infect Control Hosp Epidemiol 2010; 31(12):1308-1310

(C) 2010 by The Society for Healthcare Epidemiology of America. All rights reserved. 0899-823X/2010/3112-0020\$15.00. DOI: $10.1086 / 657581$

\section{REFERENCES}

1. Kohn WG, Collins AS, Cleveland JL, et al; Centers for Disease Control and Prevention. Guidelines for infection control in dental health-care settings-2003. MMWR Morb Mortal Wkly Rep 2003;52(RR-17):1-61.

2. Research Committee of the Society of Healthcare Epidemiology of America. Enhancing patient safety by reducing healthcare-associated infections: the role of discovery and dissemination. Infect Control Hosp Epidemiol 2010;31:118-123.

3. Social, Health and Family Affairs Committee. The handling of the H1N1 pandemic: more transparency needed. Council of Europe Parliamentary Assembly website. http://assembly.coe.int/CommitteeDocs/2010/ 20100329_MemorandumPandemie_E.pdf. Published March 23, 2010. Accessed May 20, 2010.

4. Petti S, Tarsitani G. Detection and quantification of dental unit water line contamination by oral streptococci. Infect Control Hosp Epidemiol 2006;27:504-509.

5. Jones DJ, Munro CL. Oral care and the risk of bloodstream infections in mechanically ventilated adults: a review. Intensive Crit Care Nurs 2008;24:152-161.

6. Pankhurst CL, Coulter WA. Do contaminated dental unit waterlines pose a risk of infection? J Dent 2007;35:712-720.

7. Schel AJ, Marsh PD, Bradshaw DJ, et al. Comparison of the efficacies of disinfectants to control microbial contamination in dental unit water systems in general dental practices across the European Union. Appl Environ Microbiol 2006;72:1380-1387.

8. Cottone JA, Terezhalmy GT, Molinari JA. Practical infection control in dentistry. Baltimore, MD: Williams \& Wilkins, 1996.

9. Redd JT, Baumbach J, Kohn W, Nainan O, Khristova M, Williams I. Patient-to-patient transmission of hepatitis B virus associated with oral surgery. J Infect Dis 2007;195:1311-1314.

10. Cunha BA, Thekkel V, Krilov L. Nosocomial swine influenza (H1N1) pneumonia: lessons learned from an illustrative case. J Hosp Infect 2010; 74:278-281.

11. Polimeni A, Petti S. Cross-infection control and sterilization in dentistry [in Italian]. Italian Ministry of Health website. http://www.quadernidella salute.it/download/download/5-settembre-ottobre-2010quaderno.pdf.

12. Council of Europe. Council recommendation of 9 June 2009 on patient safety, including the prevention and control of healthcare associated infections. EUR-Lex website. http://eur-lex.europa.eu/LexUriServ/Lex UriServ.do? uri = CELEX:32009H0703(01):EN:NOT. Published June 9, 2009.

13. Commission of the European Communities. Communication from the Commission on the precautionary principle. European Commission website. http://ec.europa.eu/dgs/health_consumer/library/pub/pub07_en.pdf. Published February 2, 2000. Accessed May 25, 2010. 
14. Shah SM, Merchant AT, Dosman JA. Percutaneous injuries among dental professionals in Washington State. BMC Public Health 2006;6:269.

\section{Validity of Self-Declared Teaching Status in Mandatory Public Reporting}

To the Editor-Mandatory public reporting programs using the National Healthcare Safety Network (NHSN) have noticed discrepancies between hospital characteristics versus NHSN designation of teaching status. The NHSN variable coding teaching status of each hospital is self declared and subjectively defined; it has not been verified against other sources of information. Accreditation of medical teaching programs is well established, so it should be possible to confirm teaching status in a more objective manner.

Sackett ${ }^{1}$ was among the first to describe referral filter bias, noting that referrals of patients from primary to tertiary care facilities leads to increasing prevalence of more-severe or unusual cases, which increases the likelihood of adverse or unfavorable outcomes. That is why hospitals with teaching programs for medical students, interns, residents, and fellows need to be distinguished from other hospitals. Because academic medical centers have both advanced care capabilities and the desire to provide a rich teaching environment by attracting complex cases, their patient case-mix is recognized as different. NHSN includes teaching status among the variables it uses to adjust for inherent differences in the challenges faced by the wide range of hospitals using that system for reporting healthcare-associated infection. The need to compensate for such differences is not just theoretical. Trends in healthcare-associated infection have long been noted as different in small hospitals, community hospitals, larger regional hospitals, and teaching hospitals. ${ }^{2}$ Various case-mix index approaches have been used by different agencies to identify where a higher proportion of complex cases justifies higher rates of reimbursement in medical care insurance systems, such as the one used by the US Centers for Medicare and Medicaid Services. ${ }^{3}$

Information on self-reported teaching status was obtained from NHSN for the hospitals participating in our state's mandatory public reporting program. Objective information on accredited hospital teaching programs in our state was obtained from the Association of American Medical Colleges (AAMC) website (for undergraduate medical student education) and the Accreditation Council for Graduate Medical Education (ACGME) website (for physicians after completion of undergraduate medical education to prepare for independent practice in a medical specialty or subspecialty)., ${ }^{4,5} \mathrm{We}$ classified accredited level of involvement per NHSN as none, major (undergraduate medical students), or graduate (interns, residents, and fellows). We classified the extent of in- volvement per ACGME as graduate (at least 4 months on site during 2-year programs or at least 6 months during programs lasting more than 2 years) or limited (shorter durations).

Five hospitals that are enrolled in our state's mandatory reporting program were excluded from this analysis because of insufficient information available in their NHSN survey module. Among the remaining 56 hospitals, a subjective claim in NHSN of any versus no teaching status matched the objective accredited teaching program status for 44 (positive predictive value, $75 \%$, and negative predictive value, $81 \%$ ). Twelve discordant pairs did not show evidence of significant differential misclassification ( $P=.77$, McNemar's $\chi^{2}$ test) ${ }^{6}$ More detailed examination (Table 1) shows modest concordance (unweighted $\kappa=0.4$ ). ${ }^{6}$ Most of the hospitals participating in teaching programs involve residencies or fellowships rather than medical students. There was misclassification in both presence of any teaching activity as well as in distinction between major undergraduate versus graduate activity.

It has long been recognized that infection control program resources and the complexity of patient conditions differ between small community hospitals and large academic medical centers. Before NHSN opened enrollment to all facilities, its forerunner (the National Nosocomial Infections Surveillance system) was known to overrepresent large academic centers, and few other study groups focused on smaller hospitals. ${ }^{7,8}$ NHSN now serves as the major secure data network for statewide mandatory public reporting programs, so accurate classification of teaching status is important to ensure fair representation of all hospitals. Hospitals joining NHSN fill in a survey screen that asks them to indicate whether they are affiliated with a medical school (yes or no) and, if yes, to characterize their involvement as one of the following 3 types: (1) major (facility is an important part of the teaching program of the medical school, and the majority of medical students rotated through multiple clinical services), (2) graduate (facility is used by the medical school for graduate training programs only - that is, residency and/or fellowships), or (3) limited (facility is used in the medical school's teaching program to a limited extent only). There is no definition of what constitutes "important" and no specification of duration in a facility being "used," which leaves considerable room for interpretation.

Our initial efforts reclassified teaching status solely on the

TA B LE 1. Cross-Tabulation of Level of Medical Teaching Programs in Acute Care Hospitals

\begin{tabular}{lccccr}
\hline \multirow{2}{*}{$\begin{array}{l}\text { Subjective } \\
\text { claim }\end{array}$} & No teaching & Limited & Graduate & Major & Total \\
\cline { 2 - 6 } & 29 & 5 & 2 & 0 & 36 \\
No teaching & 4 & 0 & 4 & 0 & 8 \\
Limited & 0 & 1 & 5 & 0 & 6 \\
Graduate & 1 & 0 & 2 & 3 & 6 \\
Major & 34 & 6 & 13 & 3 & 56 \\
Total & & & & &
\end{tabular}

